\title{
Contraceptive Use Among Women Living with HIV and AIDS Receiving Care at Secondary and Tertiary Health Care Facilities in Ibadan, Nigeria
}

\author{
Adenuga Faidat Adesola ${ }^{1, *}$, Bakarey Adeleye Solomon ${ }^{2}$, Titiloye Musibau Ayoade ${ }^{3}$, \\ Oladepo Oladimeji ${ }^{3}$, Ngene Samuel Osobuchi ${ }^{4}$ \\ ${ }^{1}$ Department of Obstetrics and Gynaecology, University of Ibadan, Ibadan, Nigeria \\ ${ }^{2}$ Institute for Advanced Medical Research and Training, University of Ibadan, Ibadan, Nigeria \\ ${ }^{3}$ Department of Health Promotion and Education, University of Ibadan, Ibadan, Nigeria \\ ${ }^{4}$ Department of Epidemiology and Medical Statistics, University of Ibadan, Ibadan, Nigeria \\ Email address: \\ dasfadolad@gmail.com (A. F. Adesola) \\ ${ }^{*}$ Corresponding author
}

\section{To cite this article:}

Adenuga Faidat Adesola, Bakarey Adeleye Solomon, Titiloye Musibau Ayoade, Oladepo Oladimeji, Ngene Samuel Osobuchi. Contraceptive Use Among Women Living with HIV and AIDS Receiving Care at Secondary and Tertiary Health Care Facilities in Ibadan, Nigeria. American Journal of Clinical and Experimental Medicine. Vol. 5, No. 6, 2017, pp. 218-223. doi: 10.11648/j.ajcem.20170506.16

Received: October 30, 2017; Accepted: November 14, 2017; Published: December 18, 2017

\begin{abstract}
Contraceptive use is a form of family planning and it is one practice among the most important health decisions that many people make and this does not exclude women living with HIV/AIDS. Lack of adequate information on available contraceptive methods and restriction of choices are the major constraints for contraceptive users to obtain a method that suits their need. Consequently, this study was designed to assess contraceptive use among women living with HIV and AIDS receiving care at secondary and tertiary health care facilities in Ibadan, Nigeria. A cross-sectional study using systematic sampling technique was conducted to select 350 consenting women among HIV positive women receiving care in two health facilities in Ibadan, Nigeria. A pre-tested interviewer administered questionnaire was used to obtain information on respondent's socio-demographic characteristics, contraceptive usage and level of satisfaction of modern contraceptive method. Data were analyzed using SPSS version 22. Chi-square statistic was used to test associations between categorical variables at a level of statistical significance of $5 \%$. The mean age of respondents was $37.0 \pm 8.5$ years and about $87.0 \%$ were currently married. The current prevalence of contraceptive was $67.7 \%$. Condom was the most currently preferred contraceptive method $(54.0 \%)$, followed by injectable $(12.2 \%)$ and oral pills $(11.0 \%)$. About $83.1 \%$ was satisfied with their current method of contraception. The most cited reason by those who were not satisfied with their current contraceptive method irregular menses $(30.0 \%)$. The factors that were significantly associated with contraceptive use were maternal age, marital status, type of marriage, level of education and parity decision $(\mathrm{P}<0.05)$. High level of contraceptive uptake and satisfaction was observed in this study. However, irregular menses was a common complaint of those who were not satisfied with their current method. Family planning programme should be incorporated as a component part of care for women living with HIV and AIDS.
\end{abstract}

Keywords: Contraceptive Use, HIV and AIDS, Ibadan

\section{Introduction}

Contraceptive use is a form of family planning and it is one practice among the most important health decisions that many people make $[1,2]$ and this does not exclude women living with HIV/AIDS. In 2015, about half of the 1.9 million new HIV positive infections worldwide were among women [3]. Although fertility and HIV rates in Nigeria are among the highest in the world as the country is rated second behind India with the number of HIV positive population globally, 
little is known about how HIV infection affects the met and unmet need for modern family planning [4]. Prevention of unintended pregnancies among HIV infected women is among the four key pillars for comprehensive prevention of mother to child transmission (PMTCT). This can only be achieved with the use of contraception to prevent unwanted pregnancy $[5,6]$.

Every year, about 1.5 million women living with HIV/AIDS become pregnant, mainly in sub-Saharan Africa [7]. This category of women has higher unmet needs for family planning (FP) for their own health and for preventing mother-to-child transmission of HIV. Prevention of unintended pregnancies among women living with HIV is the second component of the World Health Organization's four-pronged approach to comprehensive prevention of mother-to-child transmission of HIV (PMTCT) [8]. Provision of appropriate counselling and support in addition with contraceptives, to women living with HIV to meet their need for family planning and spacing of births has been shown to be a cost-effective intervention to prevent MTCT [9].

Understanding the fertility desires of HIV-infected women who know their HIV status, their contraceptive choices and the pregnancy rates is critical in meeting their reproductive health needs and preventing unwanted pregnancies. This study was therefore designed to assess the level of utilization of contraceptives among women living with HIV in Ibadan, Oyo State of Nigeria.

\section{Subjects and Method}

This is a descriptive cross-sectional survey conducted among HIV positive women receiving care at the University College hospital, (UCH) and Adeoyo Maternity Hospital Ibadan, Oyo State, Nigeria during the period March 2015 to October 2015. The sample size was estimated using the formular:

$$
\mathrm{n}=\frac{Z \alpha^{2} p q}{d^{2}}
$$

A systematic sampling technique was used to recruit women into this study. Participants were interviewed as they came into the clinic. A pretested questionnaire was used to obtained information on respondent's demographic characteristics, contraceptive use and level of satisfaction of current contraceptive choice.

Data were analyzed using the statistical Package for social Sciences version 22. All tests were carried out at $95 \%$ confidence interval with probability level of $p<0.05$ accepted as being of statistical significance. $(\alpha=0.05)$. Descriptive statistics was used to describe the general characteristics of the sample. Chi-Square test was used to determine the association between the dependent variables and some selected independent variables. The UI/UCH and Oyo State Ethical Review Board/Committee approved this study.

\section{Results}

Three hundred and fifty women were interviewed with mean age of $37.1 \pm 8.5$ years. The majority $304(86.9 \%)$ were currently married, $38(10.9 \%)$ were previously married, 8 $(2.3 \%)$ never married. About three-fourth of the women had secondary education, $55(15.7 \%)$ had primary education, 26 (7.4\%) had no formal education and $5(1.4 \%)$ had tertiary education. Regarding occupation, 210 (60\%) were traders, 44 $(12.6 \%)$ civil servants, $41(11.7 \%)$ Artisan and $13(3.7 \%)$ (Table 1).

Table 1. Respondent's socio-demographic characteristics.

\begin{tabular}{ll}
\hline Characters & N (\%) \\
\hline Age (years) & $62(17.8)$ \\
$20-29$ & $154(44.3)$ \\
$30-39$ & $132(37.9)$ \\
$>40$ & \\
Religion & $130(37.1)$ \\
Islam & $200(57.1)$ \\
Christianity & $20(5.7)$ \\
Others & \\
Marital status & $304(86.9)$ \\
Currently married & $38(10.9)$ \\
Previously married & $8(2.3)$ \\
Never married & \\
Type of marriage & $233(68.1)$ \\
Monogamy & $109(31.9)$ \\
Polygamy & \\
Level of education & $26(7.4)$ \\
No formal & $55(15.7)$ \\
Primary & $264(75.4)$ \\
Secondary & $5(1.4)$ \\
Tertiary & \\
Occupation & $210(60.0)$ \\
Trader & $41(11.7)$ \\
Artisan & $42(12.0)$ \\
Professional & $13(3.7)$ \\
Unemployed & $44(12.6)$ \\
Civil servant & \\
Spousal's level of education & $22(6.4)$ \\
No formal & $27(7.9)$ \\
Primary & $287(83.9)$ \\
Secondary & $6(1.8)$ \\
Tertiary & \\
\hline & \\
&
\end{tabular}

About $280(80 \%)$ had sexual intercourse at least once a week. Two hundred and ninety-four $(84.0 \%)$ had ever used contraceptives while about $237(67.7 \%)$ are currently using contraceptive. Condom was the most commonly used contraceptive method (Figure 1 and 2). Out of the 346 (99.9\%) who had ever been pregnant, 309 (89.3\%) had live birth, 27 (7.8\%) had induced abortion, $9(2.6 \%)$ had still birth and $1(0.3 \%)$ had spontaneous abortion. Nearly half of the decisions about parity were jointly made by the respondents and their spouses. Most of the respondents 203(58.0\%) desired more children. (Table 2). 


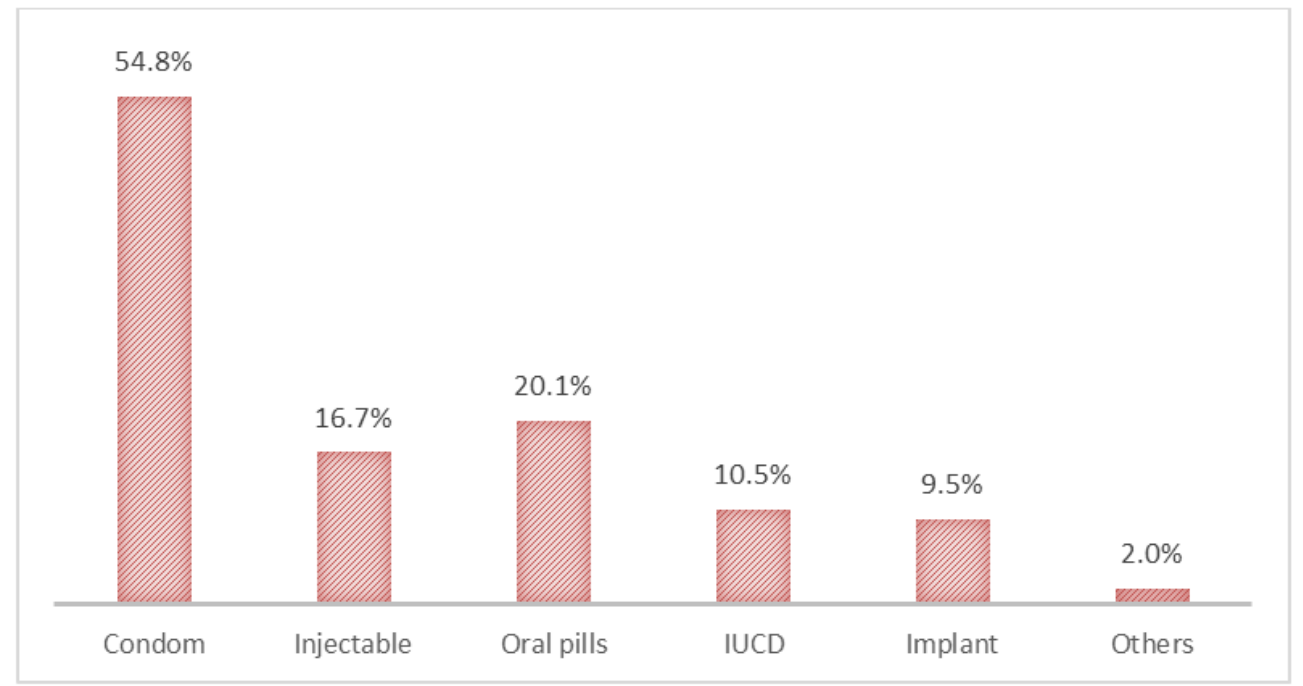

Figure 1. Ever use of contraceptives.

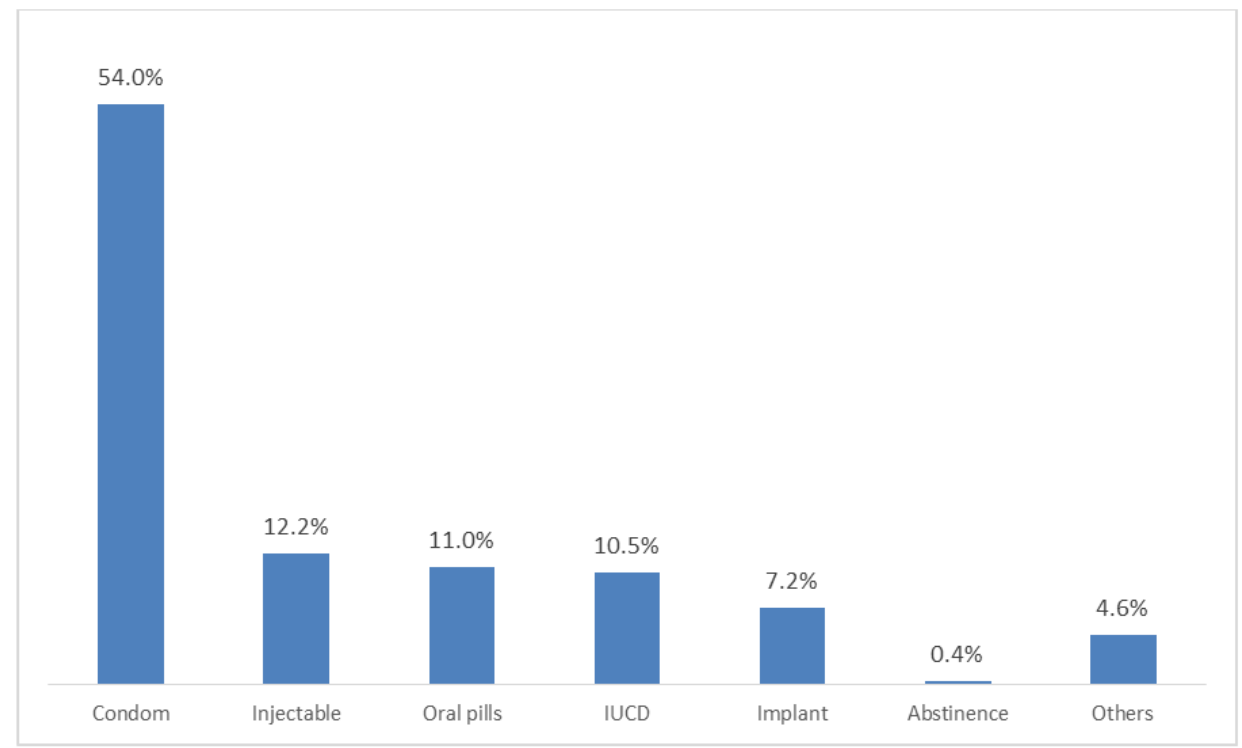

Figure 2. Current use of modern contraceptive.

Table 2. Respondent's reproductive characteristics.

\begin{tabular}{ll}
\hline Characters & $\mathbf{N}(\mathbf{\%})$ \\
\hline Frequency of sexual intercourse in a week & $70(20.0)$ \\
Rarely & $113(32.3)$ \\
Once & $71(20.3)$ \\
Twice & $50(14.3)$ \\
$3-4$ times & $46(13.1)$ \\
$>4$ times & \\
Ever used contraceptive & $294(84.0)$ \\
Yes & $56(16.0)$ \\
No & \\
Currently using contraceptive & $237(67.7)$ \\
Yes & $113(32.3)$ \\
No & \\
Number of previous pregnancy & $4(1.1)$ \\
None & $155(44.3)$ \\
$1-3$ & $161(46.0)$ \\
$4-6$ & $30(8.6)$ \\
$>6$ & $309(89.3)$ \\
Outcome of previous pregnancy & \\
Live birth & \\
\hline
\end{tabular}




\begin{tabular}{ll}
\hline Characters & $\mathbf{N}(\mathbf{\%})$ \\
\hline Induced abortion & $27(7.8)$ \\
Still birth & $9(2.6)$ \\
Spontaneous abortion & $1(0.3)$ \\
Number of previous delivery & $5(1.4)$ \\
None & $211(60.3)$ \\
$1-3$ & $111(31.7)$ \\
$4-6$ & $23(6.6)$ \\
$>6$ & $7(2.0)$ \\
Number of living children & $239(68.3)$ \\
None & $86(24.6)$ \\
$1-3$ & $18(5.1)$ \\
$4-6$ & \\
$>6$ & $147(42.0)$ \\
Number of more children desired & $144(41.1)$ \\
None & $59(16.9)$ \\
$1-2$ & \\
$>3$ & $98(28.0)$ \\
Decision about parity & $79(22.6)$ \\
Self & $157(44.9)$ \\
Spouse & $16(4.6)$ \\
Joint (couple) & \\
In-laws & \\
\hline
\end{tabular}

One hundred and ninety-seven $(83.1 \%)$ of the women were satisfied with their current contraceptive method. Most women who were not satisfied with their current method complained of having irregular menses (30\%) (Table 3).

Table 3. Satisfaction with current method.

\begin{tabular}{ll}
\hline Variables & Frequency $(\%)$ \\
\hline Satisfied with current method $(\mathrm{n}=237)$ & $197(83.1)$ \\
Yes & $20(8.5)$ \\
No & $20(8.4)$ \\
No response & \\
Reasons for non-satisfaction $(\mathrm{n}=20)$ & $6(30.0)$ \\
Irregular menses & $3(15.0)$ \\
No reason & $1(5.0)$ \\
Fear of infertility & $10(50.0)$ \\
No response & \\
\hline
\end{tabular}

Current usage of contraceptive is significantly associated with age, marital status, type of marriage, respondent's level of education and decision about parity $(\mathrm{P}<0.05)$. Higher usage of contraceptive was evident among those aged 20-29 years, the never married, respondents from monogamous home, secondary education and made joint decision about parity. Table (4)

Table 4. Association between current contraceptive usage and respondent's characteristics.

\begin{tabular}{|c|c|c|c|}
\hline \multirow[t]{2}{*}{ Characters } & \multicolumn{2}{|c|}{ Currently using contraceptives } & \multirow[t]{2}{*}{ P-value } \\
\hline & Yes $(\%)$ & No (\%) & \\
\hline \multicolumn{4}{|l|}{ Age (years) } \\
\hline $20-29$ & 82.3 & 17.7 & \multirow{3}{*}{$0.002 *$} \\
\hline $30-39$ & 70.1 & 29.9 & \\
\hline$>40$ & 57.6 & 42.4 & \\
\hline \multicolumn{4}{|l|}{ Religion } \\
\hline Islam & 61.5 & 38.5 & \multirow{3}{*}{0.086} \\
\hline Christianity & 72.5 & 27.5 & \\
\hline Others & 60.0 & 40.0 & \\
\hline \multicolumn{4}{|l|}{ Marital status } \\
\hline Currently married & 71.4 & 28.6 & \multirow{3}{*}{$0.000^{*}$} \\
\hline Previously married & 34.2 & 65.8 & \\
\hline Never married & 87.5 & 12.5 & \\
\hline \multicolumn{4}{|l|}{ Type of marriage } \\
\hline Monogamy & 70.8 & 29.2 & \multirow[t]{2}{*}{$0.040^{*}$} \\
\hline Polygamy & 59.6 & 40.4 & \\
\hline \multicolumn{4}{|l|}{ Level of education } \\
\hline No formal & 61.5 & 38.5 & \multirow{3}{*}{$0.003^{*}$} \\
\hline Primary & 52.7 & 47.3 & \\
\hline Secondary & 72.3 & 27.7 & \\
\hline
\end{tabular}




\begin{tabular}{llll}
\hline Characters & Currently using contraceptives & & P-value \\
\hline & Yes (\%) & No (\%) & 80.0 \\
\hline Tertiary & 20.0 & & 0.277 \\
Spousal's level of education & & 45.5 & \\
No formal & 54.5 & 44.4 & \\
Primary & 55.6 & 30.7 & 0.148 \\
Secondary & 69.3 & 33.3 & \\
Tertiary & 66.7 & 35.7 & \\
Occupation & & 36.6 & \\
Trader & 64.3 & 21.4 & \\
Artisan & 63.4 & 38.5 & $0.023^{*}$ \\
Professional & 78.6 & 20.5 & \\
Unemployed & 61.5 & & \\
Civil servant & 79.5 & 33.7 \\
Decision about parity & & 44.3 & \\
Self & 66.3 & 24.8 & \\
Spouse & 55.7 & 37.5 & \\
Joint (Couple) & 75.2 & & \\
In-laws & 62.5 & & \\
\hline
\end{tabular}

*=Statistically significant at $\mathrm{P}<0.05$

\section{Discussion}

This study was conducted among HIV seropositive women receiving care in two health facilities in Ibadan metropolis revealed that most respondents were between age 30 and 39 years with mean age of $37.1 \pm 8.5$ years. This is consonance with the report of [10] among antiretroviral therapy patients in Ibadan, Nigeria. Nearly, nine out of every ten women in this study were currently married. This is in line with previous studies conducted among rural women in Ikeji, Arakeji, South West Nigeria [11] and among antenatal attendees in Uyo, South South, Nigeria [12]. The preponderance of married people in this study is higher probably because nearly all the women had ever been pregnant and are expected to have been married.

Most women in this study had ever or were currently using contraceptives as opposed to the existing evidence that contraceptive uptake has been abysmal in Nigeria [11, 1315]. A plausible reason for the high contraceptive use in this study is the increased awareness campaign of contraceptives among people living with HIV and AIDS. The most common contraceptive used by respondents in this study was condom. This is similar with the report of previous studies [16]. Some authors have suggested that condoms are cheap, accessible, quick to use, with minimal side effects $[17,18]$. This could be a possible reason for the high prevalence of condom use in this study.

Interestingly, this study found a negative association between contraceptive use and age. This is similar with the findings of other authors [19]. The finding that utilization of contraceptive was higher among younger respondents than older respondents is an indication of the availability of a youth friendly contraceptive. Also, this finding suggest a higher prevalence of contraceptives among single women than ever married women. This finding substantiates the assertion that contraceptive usage is higher among unmarried sexually active women than married sexual active women $[13,20,21]$. Never married sexually active women were increasingly using contraceptives due to the recent increased awareness of HIV/AIDS in secondary schools, higher institutions and youth centres in the communities. Condom is most preferred contraceptives by this category of women because they may be ashamed of seeking health care in family planning clinics. Also, it is cheap and does not require complex medical prescription.

Surprisingly, this study found that women with tertiary education had the least contraceptive prevalence compared to others. This is in contrast to the pool of evidence established by previous studies that found a positive association between level of education attained by women and prevalence of contraceptives [13, 22-25]. This anomaly can be attributed to the low population of women with tertiary education in this study.

Furthermore, this study found that most women were satisfied with their current contraceptive method. This is in line with the study among women in Kumasi, Ghana [26] and Mozambique [27]. About one in ten women complained about irregular menses compared to one in five among women in Kumasi, Ghana [26].

\section{Conclusion}

Most respondents in this study had ever used and were currently using contraceptives. Condom was the most ever used and currently used method of contraception while implant was the least ever used method of contraception. Current contraceptive use was significantly associated with age, marital status, type of marriage, level of education and parity decision. Most women were satisfied with their current method of contraception. The most cited reason for nonsatisfaction with current contraceptive method was experience of irregular menses while fear of irregular menses was the least cited reason.

The questionnaire used for this study had some sensitive questions. Hence, social desirability bias was a major limitation of this study. 


\section{References}

[1] United States Agency for International Development LongActing and permanent methods of Contraception: Meeting Clients' needs. 2006, Retrived on September 2015 from http://pdf.usaid.gov/pdf_docs/Pnadi070.pdf: Washington, DC.

[2] R. Smith, L. Ashford, J. Gribble and D. Clifton D. Family planning saves lives. 2009.

[3] Joint United Nations Programme on HIV/AIDS. United Nations Political Declaration on Ending AIDS sets world on the Fast-Track to end the epidemic by 2030. 2016, Retrieved on 27th October, 2017 from

http://www.unaids.org/en/resources/presscentre/pressreleasean dstatementarchive/2016/june/20160608_PS_HLM_PoliticalD eclaration.

[4] Ethiopia Demographic Health Survey, Health Survey: Addis Ababa. Ethiopia and Calverton, Maryland, USA: central statistics agency and ORC macro, 2011.

[5] T. Delvaux and C. Nöstlinger, Reproductive choice for women and men living with HIV: contraception, abortion and fertility. Reproductive health matters, 2007. 15(29): p. 46-66.

[6] Federal Ministry of Health, Guidelines for Prevention of Mother-to-Child Transmission of HIV in Ethiopia. Addis Ababa: Federal HIV/AIDS Prevention and Control Office 38., 2011.

[7] Joint United Nations Programme on HIV/AIDS UNAIDS report on the global AIDS epidemic. 2013, Retrieved on 27th October, 2017 from

http://www.unaids.org/en/resources/presscentre/pressreleasean dstatementarchive/2016/june/20160608_PS_HLM_PoliticalD eclaration.

[8] World Health Organisation, Improving Access to Quality care in Family Planning: Medical eligibility criteria for contraceptive use. 2004: Geneva, Switzerland.

[9] R. Reynolds, B Janowitz, R. Wilcher, W. Cates. Contraception to prevent HIV-positive births: current contribution and potential cost savings in PEPFAR countries. Sexually transmitted infections, 2008. 84(Suppl 2): p. ii49-ii53.

[10] J. O. Akinyemi, O. A. Awolude, I. F. Adewole, P. J. Kanki, Akinyemi, J. O., et al., Condom use among antiretroviral therapy patients in Ibadan, Nigeria. The Journal of Infection in Developing Countries, 2010. 4(08): p. 495-502.

[11] E. Odusina, D. Ugal, and O. Olaposi. Socioeconomic status, contraceptive knowledge and use among rural women in Ikeji Arakeji, Osun State, Nigeria. Afro Asian Journal of Social Sciences, 2012. 3(3. 2): p. 1-10.

[12] A. V. Umoh and M. G. Abah. Contraception awareness and practice among antenatal attendees in Uyo, Nigeria. Pan African Medical Journal, 2011. 10.

[13] F. C. Igbodekwe, O. Oladimeji, J. E. Oladimeji, I. A. Adeoye, O. M. Akpa, L. Lawson. Utilisation of modern contraceptive among women of childbearing age in resource constraint setting: evidence from 2008 National Demographic and Health Survey in Nigeria. Journal of Health Science, 2014. 4(3): p. 72-78.
[14] A. Akinyemi, S. Adedini, S. Hounton, A. Akinlo, O. Adedeji, O. Adonri, et al. Contraceptive use and distribution of highrisk births in Nigeria: a sub-national analysis. Global health action, 2015. 8(1): p. 29745.

[15] J. E. Eko, K. O. Osonwa, N. C. Osuchukwu, D. A. Offiong. Prevalence of Contraceptive use among women of reproductive age in Calabar Metropolis, Southern Nigeria. International Journal of Humanities and Social Science Invention (IJHSSI), 2013. 2(6).

[16] B. Oye-Adeniran, I. Adewole, K. Odeyemi, E. Ekanem, A. Umoh. Contraceptive prevalence among young women in Nigeria. Journal of Obstetrics and Gynaecology, 2005. 25(2): p. 182-185.

[17] J. Cleland and M. M. Ali. Sexual abstinence, contraception, and condom use by young African women: a secondary analysis of survey data. The Lancet, 2006. 368(9549): p. 17881793.

[18] P. Maharaj and Cleland J. Condoms become the norm in the sexual culture of college students in Durban, South Africa. Reproductive health matters, 2006. 14(28): p. 104-112.

[19] A. Etokidem, W. Ndifon, J. Etowa, E. Asuquo. Family planning practices of rural community dwellers in cross River State, Nigeria. Nigerian Journal of Clinical Practice, 2017. 20(6): p. 707-715.

[20] A. M. Abasiattai, E. Etukumana, N. M. Utuk, A. Umoiyoho. Awareness and Practice of Contraception Among Antenatal Attendees in a Tertiary Hospital in South-South Nigeria. TAF Preventive Medicine Bulletin, 2011. 10(1): p. 29-34.

[21] S. Chae and V. Woog, Barriers to Women's Contraceptive Use in Benin. 2016, Guttmacher Institute: Retrieved 26th October, 2017 from https://www.guttmacher.org/report/barrierswomens-contraceptive-use-benin.

[22] M. M. Khan, M. E. Hossain, and M. N. Hoq. Determinants of contraception use among female adolescents in Bangladesh. Asian social science, 2012. 8(12): p. 181.

[23] E. Nketiah-Amponsah, E. Arthur, and A. Abuosi, Correlates of contraceptive use among Ghanaian women of reproductive age (15-49 years). African journal of reproductive health, 2012. 16(3): p. 154-169.

[24] S. H. Nyarko. Prevalence and correlates of contraceptive use among female adolescents in Ghana. BMC women's health, 2015. 15(1): p. 60 .

[25] B. L. Solanke. Factors influencing contraceptive use and nonuse among women of advanced reproductive age in Nigeria. Journal of Health, Population and Nutrition, 2017. 36(1): p. 1.

[26] D. O. Laryea, F. Ankobeah, E. S. Morhe, Y. A. Amoako, K. Spangenberg. Characteristics and contributory factors for injectable contraceptive usage among women in Kumasi, Ghana. Contraception and Reproductive Medicine, 2016. 1(1): p. 8.

[27] L. Chavane, M. Dgedge, P. Bailey, O. Loquiha, M. Aerts, M. Temmerman. Assessing women's satisfaction with family planning services in Mozambique. J Fam Plann Reprod Health Care, 2017. 43(3): p. 222-228. 